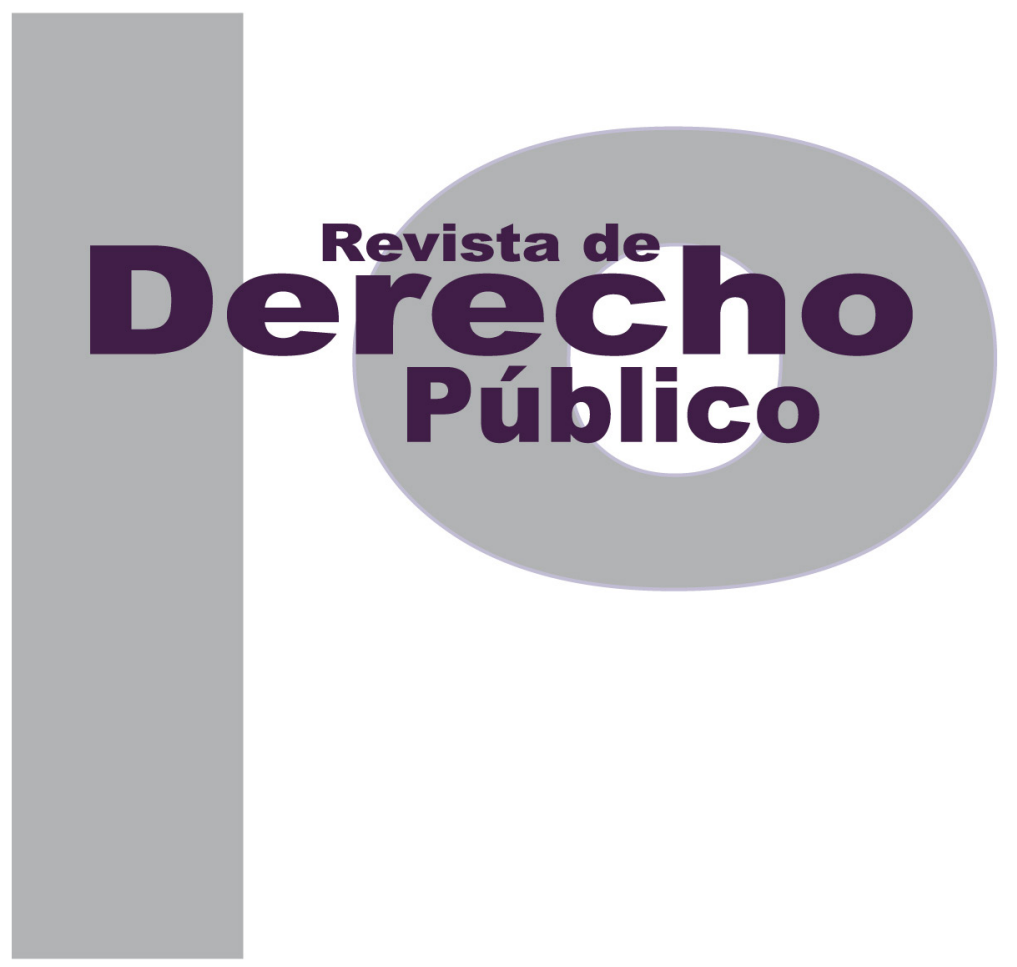

INTERRELACIÓN ENTRE EL IUS COGENS Y EL DERECHO BLANDO. DERECHOS SOCIALES Y RESPONSABILIDAD SOCIAL CORPORATIVA EN LA JUSTICIA TRANSICIONAL

EMERSON CEPEDA RodríGueZ

Artículo de reflexión

DOI: http://dx.doi.org/10.15425/redepub.36.2016.02

Universidad de los Andes

Facultad de Derecho

Rev. derecho publico No. 36

enero - junio de 2016. e-ISSN 1909-7778 


\title{
Interrelación entre el ius cogens y el derecho blando. Derechos sociales y responsabilidad social corporativa en la justicia transicional
}

\section{Resumen}

A través de las sentencias de la Corte Interamericana de Derechos Humanos y la Corte Constitucional de Colombia se aborda la ampliación del derecho imperativo (ius cogens) como fuente material del derecho internacional; asimismo, se analiza la obligatoriedad del derecho blando (soft law), principalmente su importancia en la interpretación judicial y fundamentación de los intereses protegidos por el ius cogens, como los derechos humanos. Criterios que establecen lineamientos específicos para abordar la justicia transicional en Colombia, más allá de un marco jurídico internacional determinado por el consentimiento estatal. Desde esta perspectiva se establece cómo las normas del derecho blando han diversificado la justicia transicional en tres sentidos: 1) la posibilidad de medidas no punitivas; 2) la aplicación de derechos económicos, sociales y culturales; y 3) la articulación con la responsabilidad social corporativa.

Palabras clave: justicia transicional, derecho blando, ius cogens, derechos económicos, sociales y culturales, responsabilidad empresarial.

\section{Interrelation between jus cogens and soft law. Social rights and corporate social responsibil- ity in transitional justice}

\begin{abstract}
Through the judgments of the inter- American Court and the Constitutional Court of Colombia, the expansion of imperative law -Jus Cogens- as material source of international law is analyzed; also, increasing obligatory of the Soft Law is explained, mainly its importance in the judicial interpretation and justification of the interests protected by Jus Cogens, such as human rights. Essential criteria that establish specific guidelines to address transitional justice in Colombia, within an international legal framework that mostly depends on State consent. From this perspective, this paper studies how the rules of Soft Law have diversified the transitional justice in three aspects: 1) the possibility of non-punitive sanctions; 2) the application of economic, social and cultural rights, and 3) the connection whit corporate social responsibility.

Keywords: Transitional Justice, Soft Law, Jus Cogens, Economic, Social and Cultural Rights, Corporate Responsibility.

\section{Inter-relação entre o ius cogens e o quase-direito. Direitos sociais e responsabilidade social corporativa na justiça transicional}

\section{Resumo}

Através das sentenças da Corte Interamericana de Direitos Humanos e a Corte Constitucional da Colômbia se aborda a ampliação do direito imperativo (ius cogens) como fonte material do direito internacional; também, se analisa a obrigatoriedade do quase-direito (soft law), principalmente sua importância na interpretação judicial e fundamentação dos interesses protegidos pelo ius cogens, como os direitos humanos. Critérios que estabelecem lineamentos específicos para abordar a justiça transicional na Colômbia, para além de um marco jurídico internacional determinado pelo consentimento estatal. Desde esta perspectiva se estabelece como as normas do quase-direito têm diversificado a justiça transicional em três sentidos: 1) a possibilidade de medidas não punitivas; 2) a aplicação de direitos econômicos, sociais e culturais; e 3) a articulação com a responsabilidade social corporativa.

Palavras-chave: justiça transicional, quase-direito, ius cogens, direitos econômicos, sociais e culturais, responsabilidade empresarial. 


\title{
Interrelación entre el ius cogens y el derecho blando. Derechos sociales y responsabilidad social corporativa en la justicia transicional*
}

\author{
EMERSON CEPEDA RODRÍGueZ ${ }^{1}$
}

\section{SUMARIO}

Introducción - I. VISIONES EN TORNO AL IUS COGENS, EL DERECHO BLANDO Y LA JUSTICIA TRANSICIONAL - A. IUS COgens - B. Derecho blando - C. Justicia transicional - II. INCORPORACIÓN DEL IUS COGENS Y EL DERECHO BLANDO EN LA CORTE INTERAMERICANA DE DERECHOS HUMANOS Y LA CORTE CONSTITUCIONAL - A. Ius cogens - 1 . Corte Interamericana de Derechos Humanos - 2. Corte Constitucional - B. Derecho blando - III. INFLUENCIA DEL DERECHO BLANDO EN LA JUSTICIA TRANSICIONAL - IV. CONCLUSIONES - Referencias.

* Cómo citar este artículo: Cepeda Rodríguez, E. (Junio, 2016). Interrelación entre el ius cogens y el derecho blando. Derechos sociales y responsabilidad social corporativa en la justicia transicional. Revista de Derecho Público, (36). Universidad de los Andes (Colombia). DOI: http://dx.doi.org/10.15425/redepub.36.2016.02

1. Estudiante del Doctorado en Estudios Avanzados en Derechos Humanos, Universidad Carlos III de Madrid (España). Abogado y magíster en Derechos Humanos, Universidad Pedagógica y Tecnológica de Colombia (UPTC). Asesor de la Maestría en Derechos Humanos de la UPTC. Correo: sonemer86@gmail.com 
Introducción

La creencia que el campo jurídico se encuentra equiparado con la norma escrita ha venido desapareciendo de manera significativa. Lo que era una ciencia técnica y mecánica se transforma, dando paso al interés por construir una ciencia dinámica más cercana a los fenómenos sociales. Para citar una de esas realidades: el derecho ha dejado de ser un fenómeno local o estatal para insertarse en dinámicas globales y de más amplias repercusiones. En efecto, más allá de la existencia de procesos capitalistas transnacionales desterritorializados, perfectos y homogéneos, existen "espacios de esperanza" que permiten ver la resistencia de los espacios locales como propuestas innovadoras (Harvey, 2000).

Desde este punto de vista, se plantea una discusión respecto a aquellos escenarios que posibilitan la participación de movimientos sociales en el Sistema Internacional de Derechos Humanos, actuaciones que generalmente se consolidan en resoluciones o interpretaciones de organismos internacionales que carecen de fuerza vinculante, en la medida que estas organizaciones fueron desprovistas de esta facultad. Dentro de este contexto, al insertarse este trabajo en el derecho internacional, lo que se reconoce es su permanente evolución y ensanchamiento, ya que su estructura, sus características y finalidades dependen de la interacción y reclamos en el ámbito mundial (Diez de Velasco, 2009, p. 61). De allí que no puede abordarse bajo el entendido que es un derecho creado por los Estados y que exclusi- vamente regula las relaciones entre ellos. En cambio, desde la propuesta de Balakrishnan Rajagopal, el derecho internacional va a ser entendido como un escenario para la acción de movimientos sociales, que posibilita políticas transformativas (2010, p. 48).

Precisamente, este fenómeno si bien escapa del texto normativo de naturaleza estatal o institucional, también tiene cimientos dentro de la misma estructura normativa tradicional, analizada en este texto. En primer lugar, en el derecho internacional el artículo 53 de la Convención de Viena (CV) establece la nulidad de los tratados que estén en oposición a una norma imperativa de derecho internacional general ius cogens, naturaleza que se define en los intereses esenciales de la comunidad internacional y que debido a su carácter no necesitan del reconocimiento estatal. En segundo lugar, en el derecho constitucional colombiano, con el artículo 94 de la Constitución Nacional (CN), al señalar que la enunciación que se realice de los derechos y las garantías que están en los tratados internacionales y la Constitución no deben entenderse como negación de otros que sin estar expresamente descritos sean inherentes a la dignidad humana. Dada la prominencia de estas normas, no sorprende que temas tan importantes como el sistema de fuentes del derecho nacional e internacional se amplíen, transformen y dinamicen.

Por ello, se realiza dentro del texto una defensa del ius cogens, debido a que permite afirmar la existencia de normas abiertas y materiales, que no deben su obligatoriedad al derecho de 
los tratados. De la misma forma, se hace una apuesta respecto a la vinculatoriedad de las normas del derecho blando (también denominado programático), identificando su eficacia en la concreción del contenido de los derechos, la definición de políticas y las actuaciones desplegadas por servidores públicos.

En relación con la justicia transicional se abordarán las interpretaciones y explicaciones de la transición o la superación del conflicto, particularmente los objetivos o finalidades que debe cumplir, los cuales tendrán una influencia notoria dentro de estas metas: 1) las variables económicas que han jugado y desempeñan un papel definitivo en la generación y la reproducción de la violencia, bien sea bajo la preservación de capitales tradicionales que reafirman la concentración de la tierra, dada la centralidad de las materias primas en la economía del país o en la reafirmación de un modelo económico, en donde pierde sentido la garantía de los derechos humanos, cediendo hacia la reducción de la inversión social; 2) la crítica sobre reducción de la justicia transicional a una perspectiva eminentemente penal (Cepeda, 2013).

Al explicar el papel actual del derecho blando (soft law) y al describir realidades que per- miten corroborar su trasformación en norma imperativa a partir de la jurisprudencia interamericana y de la Corte Constitucional de Colombia, se pretende identificar herramientas adicionales para el análisis y evaluación de un posible "nuevo rol" de la justicia transicional desde una perspectiva que matiza la respuesta penal, para dar paso a la garantía de los derechos humanos y la determinación de la responsabilidad corporativa.

\section{VISIONES EN TORNO AL IUS COGENS, EL DERECHO BLANDO Y LA JUSTICIA TRANSICIONAL}

Existen varios cuestionamientos respecto al sistema tradicional de fuentes del derecho internacional contempladas en el artículo 38 del Estatuto de la Corte Internacional de Justicia $(E C I J),{ }^{2}$ que presenta las convenciones internacionales, la costumbre internacional y los principios como fuentes principales, y como fuentes auxiliares la doctrina internacional y la jurisprudencia. ${ }^{3}$ La primera controversia gira en torno a la influencia del ius cogens o norma imperativa de derecho internacional general, entendida en términos del artículo 53 (CV) como una norma aceptada y reconocida

2. Para Diez de Velasco (2009, p. 119) no son del todo satisfactorias las explicaciones del porqué el ECIJ se convierte en el texto en donde se consolidan las fuentes del derecho internacional de la comunidad internacional; no obstante, argumenta varias razones a favor del Estatuto como el carácter abierto de la Corte y su función de resolver las controversias a nivel internacional.

3. Es innegable el papel preponderante que ha adquirido la jurisprudencia en materia de derechos humanos, como la proveniente de los sistemas regionales de derechos humanos en los ordenamientos jurídicos internos. Asimismo, las sentencias de la Corte Internacional de Justicia, a pesar de la remisión que se hace respecto al artículo 59 del Estatuto, en donde se señala que solo es obligatoria para las partes; este cambio se puede sustentar en la influencia de la aplicación de la Conven- 
por la comunidad internacional, que no admite acuerdo en contrario y solo puede ser modificada por una norma con el mismo carácter, en la medida que va más allá del derecho de los tratados o del Corpus iuris fundamentado en el principio voluntarista del derecho internacional.

A pesar de ello, el contenido del concepto es objeto de muchas discusiones teóricas, cuando se señala la falta de delimitación y los peligros de su ampliación; no obstante, en este escrito se defiende la tesis que el ius cogens, entendido como aquellos intereses esenciales protegidos por la comunidad internacional, no puede ser enlistado, dado que está abierto a las dinámicas de la sociedad. De allí que también se argumenta que las finalidades del ius cogens pueden ser identificables y ampliadas, porque las comunidades han buscado crear "un conjunto de facultades e instituciones que, en cada momento histórico, concretan las exigencias de la dignidad, la libertad y la igualdad humana, las cuales deben ser reconocidas y positivizadas por los ordenamientos jurídicos a nivel nacional e internacional" (Pérez, 1995, p. 48). Igualmente, estimo que no existe ningún riesgo en su ampliación debido a que su misma consagración blinda este tipo de normas, al enviar a los Estados el mensaje que no las pueden derogar, salvo una garantía de igual o mejor categoría, por lo tanto, no pueden existir retrocesos. La razón misma del ius cogens es sustentar la creación del derecho internacional más allá de la voluntad de los Estados.

En segundo lugar, también se replantea la idea tradicional de fuentes, al existir instrumentos jurídicos que se desprenden de las competencias conferidas a organizaciones internacionales mediante los tratados que las crearon (generalmente normas que se encuentran en resoluciones) y los tratados aprobados por los Estados bajo la forma de declaraciones, por lo tanto se convierten en herramientas importantes de interpretación en aquellos casos en donde existen vacíos o dudas. En este sentido, tal y como se han venido incorporando en la jurisprudencia nacional, estas interpretaciones se sitúan en el centro de la fundamentación del ius cogens, mostrando algunos aspectos que pueden definir su estructura.

\section{A. Ius cogens}

Cebada (2002, p. 3), al analizar el fallo BarceIona Traction Light and Power Company Limited (1970) emitido por la Corte Internacional de Justicia, determina que las normas del ius cogens se caracterizan por incorporar valores esenciales de la comunidad internacional. Igualmente, se ha señalado que estas normas son inderogables, razón por la cual no puede

ción contra el Genocidio y la Convención contra la Tortura en las sentencias: República Democrática del Congo vs. Ruanda (2006), República Democrática del Congo vs. Uganda (2005), Bosnia Herzegovina vs. Serbia y Montenegro (2007) y Croacia vs. Serbia (2014). 
admitirse acuerdo en contrario y no operan circunstancias excluyentes de responsabilidad respecto a su violación (Acosta y Duque, 2008, p. 16). Su esencia, también ha sido explicada en la existencia de normas superiores a la voluntad de los Estados y los individuos (Sévane y Puppo, 2012, p. 13).

Distintos autores (Abello, 2011, p. 78; Zelada, 2002, p. 135; Schwelb en Cebada, 2002, p. 1) han mencionado el desafío que conlleva la aplicación de estas normas, ya que si bien el artículo 53 de la cv consagró el ius cogens, no se delimitó su contenido, lo que ha llevado en algunos casos extremos a que se proponga su eliminación, decisión que por sí sola resulta peligrosa e inadecuada, más aún cuando la misma CV lo prohíbe. Una justificación razonable estaría enfocada a la interpretación evolutiva del contenido, teniendo en cuenta la adaptabilidad del concepto a las necesidades sociales. Por esto, también resulta razonable la decisión de los Estados que participaron en la elaboración de la cV de crear una norma de naturaleza abierta, porque de lo contrario existiría el riesgo de crear una figura jurídica anacrónica.

A pesar de esta discusión, se han identificado algunos de esos fines, valores o principios esenciales de la comunidad internacional mediante la jurisprudencia, la opinio iuris expresada por los Estados y la doctrina (Vallarta, 2010) como: 1) los derechos de la persona (prohibición del genocidio, la tortura y la esclavitud); 2 2) el derecho a la libre autodeterminación; 3) la prohibición del uso de la fuerza; 4) el arreglo pacífico de controversias; 5) la igualdad; 6) el principio de no intervención; y 7) el derecho internacional humanitario ${ }^{5}$ (Zelada, 2002, p. 147).

En este estado, es pertinente la propuesta del exjuez de la Corte Interamericana de Derechos Humanos Cançado Trindade (2007), quien propone tres elementos para identificar el contenido del ius cogens: 1 ) el bien común (de todos los seres humanos y no de una colectividad abstracta); 2) la realización de la justicia (en el plano nacional como internacional); y 3 ) la preservación de la paz. La combinación de es-

4. El Relator de la Naciones Unidas sobre los derechos humanos y libertades fundamentales de los pueblos indígenas, en el informe 2010-2013 mencionó que las comunidades indígenas en Colombia afrontan un creciente riesgo de extinción física y cultural, en el marco de la política de defensa y seguridad, basada en el involucramiento de la población civil en el conflicto armado y en la militarización de las comunidades (Comisión Colombiana de Juristas, 2015a).

El Comité de las Naciones Unidas contra la Tortura, el 15 de mayo de 2015, en sus observaciones finales estableció la grave situación de la población carcelaria, la magnitud y la invisibilidad de la violencia sexual en contra de mujeres y niños, el uso excesivo de la fuerza en contra de quienes protestan y la ampliación de la jurisdicción penal militar. Asimismo, recomendó al Estado aceptar la competencia del Comité (Comisión Colombiana de Juristas, 2015b).

En la actualidad, un total de 35.800.000 hombres, mujeres y niños están considerados como "esclavos modernos", según el informe anual de la ONG Walk Free. India, China, Pakistán, Uzbekistán y Rusia concentran más de la mitad -el 61\%- de la esclavitud que hay en el mundo (Domínguez, 2014).

5. La aplicación de las reglas del derecho internacional humanitario en los conflictos armados internos resulta problemática, debido a que una estrategia dentro de estos es el control de la población civil (Giraldo, 2009, pp. 4 y 5). 
tos factores no solo hace posible la efectividad de las normas del ius cogens a partir de la determinación de sus elementos, sino también la permanente transformación del derecho internacional.

\section{B. Derecho blando}

Con la finalización de la Segunda Guerra Mundial el derecho internacional deja de ser eminentemente estatal y da lugar a la protección del ser humano, surgiendo el derecho penal internacional, el derecho laboral internacional, el derecho internacional del medio ambiente y el derecho internacional de los derechos humanos, que a través del sistema universal y regional establecen mecanismos de seguimiento y responsabilidad de los Estados.

Surge el derecho blando que, como se ha mencionado, tiene una gran importancia en el desarrollo del derecho internacional, así como en el replanteamiento de sus fuentes, lo que se puede representar en el hecho que uno de los textos normativos de derechos humanos sea considerado dentro de este marco: la Declaración Universal de los Derechos Humanos de 1948 (Damián, 2012, p. 27). También se puede aludir a otras normas puntuales que tienen una incidencia directa en Latinoamérica: la declaración del derecho humano al acceso a internet realizada por la Asamblea General de las Naciones Unidas en 2011 y la adopción de la Resolución (A/HRC/21/L23) que se basa en el informe del Comité Asesor de la Comisión de Derechos Humanos sobre el avance de los de- rechos de los campesinos y campesinas trabajadoras en zonas rurales, que materializan las propuestas del movimiento social "Vía campesina". Dentro de esta resolución se contempla la interlocución del campesinado como actor válido en el proceso de deliberación y decisión en todos aquellos aspectos que intervengan en su espacio vital.

Otros ejemplos, de acuerdo con Alicia Chicharro (2012, p. 21) los podemos encontrar en: "La Declaración de Río sobre Ambiente y DesarroIlo, la Declaración sobre los bosques (...) algunos de los compromisos del Convenio sobre diversidad biológica y de la Convención Marco de Naciones Unidas sobre el Cambio Climático."

En este sentido, el término derecho blando, en primer lugar, se concreta en aquellas normas que tienen un contenido programático dado que los Estados, más que obligaciones, han definido compromisos y, en segundo lugar, en las resoluciones de organismos internacionales que se expiden en virtud de las funciones otorgadas por los tratados (Toro, 2006, p. 523).

Asimismo, López y Sánchez (2008, pp. 342343), mencionan que el derecho blando a veces tiene mayor eficacia por cuanto otorga subreglas más precisas al intérprete, "al ser mecanismos de interpretación autorizada que amplifican los términos de un tratado o como estándares técnicos requeridos para la implementación de los tratados internacionales".

La apelación a este tipo de instrumentos se convertiría en obligatoria a partir de la teoría 
de los poderes implícitos de los organismos internacionales, que parte de la primacía de la realidad o de la práctica de las funciones de las organizaciones sobre la dogmática jurídica (Marín López, 2012b, p. 2), dado que las funciones, actos y normas desarrolladas se realizan dentro del marco de las atribuciones que les han sido conferidas, pudiendo ser entendidas como normas del derecho obligatorio "hard law" (Marín López, 2012b, p. 1-3).

Hechas estas precisiones es posible afirmar: en la medida que estas normas se fundamentan en las funciones de seguimiento del cumplimiento de los derechos humanos y en el establecimiento del deber ser de los mismos, pueden identificar lo que puede ser ascendido a ius cogens y establecer el alcance de los derechos humanos (Damián, 2012, p. 33).

\section{Justicia transicional}

La justicia transicional cobra vigencia cuando se transita del autoritarismo a la democracia o de la guerra hacia la paz. Sus objetivos son los siguientes: reparar los daños individuales y colectivos; conocer la verdad de los hechos; juzgar a los responsables; e implementar las medidas que garanticen que las violaciones no se vuelvan a repetir. Sin embargo, la anterior caracterización, en el contexto colombiano, esta limitada por las dificultades que ha conllevado reparar a las víctimas y juzgar a los responsables cuando persisten la violencia y los procesos de victimización primaria y secundaria, lo que puede ser calificado como una justicia transicional sin transición (Uprimny y Botero, 2006) o desde sectores más radicales, como una justicia fallida (Gamboa, 2007).

Dentro de esta concepción surgen visiones que asumen la justicia transicional de forma fragmentada, por cuanto gran mayoría de personas asimilan el concepto con indultos, amnistías o penas alternativas. No en vano el acuerdo del 23 de septiembre de 2015 sobre justicia transicional, entre el Gobierno y las Farc, en el marco de los Diálogos de Paz de La Habana, fue visto exclusivamente desde la jurisdicción para la paz y el establecimiento de las penas que deberían cumplir los responsables. Sin embargo, también existen visiones holísticas de lo que debe realizar cualquier tipo de proceso o mecanismo de justicia, que pasan por la reparación de víctimas y llegan hasta el reconocimiento de los ya aceptados principios de indivisibilidad e interdependencia de los derechos humanos, como por ejemplo, ratificar la obligación que tienen los Estados de satisfacer derechos económicos, sociales y culturales.

No obstante, es necesario advertir que el cumplimiento de estos fines resulta difícil en contextos en donde se ha degradado la violencia, se han generado millones de víctimas y presentado dificultades para la judicialización y la reparación integral de víctimas. La pretensión en estos momentos, tal y como lo menciona Uprimny (2013) explicando a Pablo de Greiff, es reconocer una "justicia imperfecta", en donde si bien se deben reforzar cada uno de los derechos de las víctimas, también im- 
plica "decisiones dolorosas y dilemas trágicos (...) la ponderación concreta entre el deber de investigar y sancionar, con las posibilidades de la paz y la garantía de los otros derechos de las víctimas" (p. 7).

\section{INCORPORACIÓN DEL IUS COGENS $Y$ EL DERECHO BLANDO EN LA CORTE INTERAMERICANA DE DERECHOS HUMANOS Y LA CORTE CONSTITUCIONAL}

\section{A. Ius cogens}

La Corte Interamericana de Derechos Humanos (en adelante Corte IDH) y la Corte Constitucional de Colombia han utilizado la categoría ius cogens y ampliado los objetivos que busca proteger este tipo de normas. En este sentido, los pronunciamientos se han referido a los contenidos clásicos del ius cogens, como la prohibición de los delitos de lesa humanidad (el homicidio, la tortura, la desaparición forzada y la violencia sexual) y las violaciones al derecho internacional humanitario, pero además han incluido el principio de igualdad y no discriminación, la protección de los derechos de los niños, las garantías judiciales y la protección judicial. Adicionalmente, se han generado mayores avances en su construcción dogmática, y se ha incorporado el derecho a la vida entendido en sus dos esferas: en la obligación negativa de no privar a nadie de la vida y la obligación positiva de tomar todas las medidas para asegurar que no sea violado; de igual importancia resulta el derecho de la responsabilidad internacional de los Estados.
1. Corte Interamericana de Derechos Humanos

En la sentencia de los Niños de la Calle vs. Guatemala (1999), la Corte IDH conoció sobre un patrón de violaciones sistemáticas de derechos humanos (amenazas, detenciones, tratos crueles, inhumanos y degradantes y homicidios) que tenían como finalidad contrarrestar la delincuencia y vagancia juvenil. En el voto razonado del juez Cançado Trindade (1999) se consolida y expande la doctrina del ius cogens. Entre los argumentos sobresale la redefinición del derecho a la vida, toda vez que ya no puede ser entendido de forma restringida como prohibición arbitraria de vida física, debiendo ampliarse también a las circunstancias que igualmente le dan sentido a la existencia, representada en aquellas medidas positivas de protección del Estado en donde, no cabe duda, es necesaria la garantía de otros derechos humanos.

En este sentido, Cançado Trindade (1999) menciona que es deber del Estado proteger la vida de las personas en situación de riesgo, como los niños de la calle, por considerar que la violación del derecho a la vida no solo se limita al homicidio, sino que se extiende a la privación del derecho de vivir dignamente, razón por la cual adquiere vigencia la interrelación e indivisibilidad de todos los derechos humanos, que en otras palabras son la garantía de los derechos civiles y políticos, así como de los derechos económicos, sociales y culturales.

Posteriormente, en la sentencia del caso Tibi vs. Ecuador (2004) la Corte IDH determina 
la responsabilidad del Estado por la privación injusta de la libertad, llevada a cabo por agentes de la Interpol, que se prolongó a 27 meses, sin que mediara orden judicial o existieran pruebas. Frente a estos hechos la Corte plantea que las normas del ius cogens deben protegerse aun en las circunstancias más difíciles (párr. 143); y que adicionalmente a las reglas de interpretación consagradas en el artículo 31 de la $\mathrm{CV},{ }^{6}$ también es necesario avanzar en una interpretación evolutiva de los instrumentos internacionales de protección (párr. 144).

Como en el anterior caso, el voto razonado del juez Cançado Trindade (2004) reviste vital importancia, ya que si bien se refiere a la prohibición de la tortura como norma del ius cogens, precisa cuatro características en la construcción dogmática: 1) las normas imperativas no se deben limitar a las normas convencionales $y$ al derecho de los tratados; 2) el ius cogens es una categoría abierta y fuente material, que se expande porque despierta la conciencia jurídica universal (párr. 31), alcanzando, por tanto, el valor de un derecho internacional verdaderamente universal; 3) la responsabilidad internacional de los Estados hace parte del ius cogens; 4) los efectos del ius cogens son horizontales y verticales, en el sentido que pueden invalidar normas de derecho internacional y derecho interno (párr. 32).

Un ejemplo concreto de aplicación del ius cogens es el caso Almonacid Arellano y otros vs. Chile (2006). En esta ocasión la Corte IDH analizó la Ley de Amnistía en el contexto de la dictadura, que tenía como propósito dejar de investigar y sancionar las ejecuciones y desapariciones forzadas de 3.197 personas que ocurrieron en el gobierno militar, así como las 33.221 detenciones, contexto en el que se enmarca el asesinato del señor Almonacid Arellano. La Corte argumentó que aunque Chile no había firmado la Convención sobre la imprescriptibilidad de los crímenes de guerra y lesa humanidad, era de obligatorio cumplimiento para el Estado chileno por constituir una categoría de derecho internacional general (ius cogens) (párr. 153). De allí que el Estado no puede argumentar la prescripción, la irretroactividad de la ley penal ni el principio non bis in ídem, así como cualquier excluyente de responsabilidad, para excusarse de su deber de investigar y sancionar los responsables.

6. 31. Regla general de interpretación. 1. Un tratado deberá interpretarse de buena fe conforme al sentido corriente que haya de atribuirse a los términos del tratado en el contexto de estos y teniendo en cuenta su objeto y fin. 2. Para los efectos de la interpretación de un tratado, el contexto comprenderá, además del texto, incluidos su preámbulo y anexos: a) todo acuerdo que se refiera al tratado y haya sido concertado entre todas las partes con motivo de la celebración del tratado: b) todo instrumento formulado por una o más partes con motivo de la celebración del tratado y aceptado por las demás como instrumento referente al tratado; 3. Juntamente con el contexto, habrá de tenerse en cuenta: a) todo acuerdo ulterior entre las partes acerca de la interpretación del tratado o de la aplicación de sus disposiciones; b) toda práctica ulteriormente seguida en la aplicación del tratado por la cual conste el acuerdo de las partes acerca de la interpretación del tratado; c) toda forma pertinente de derecho internacional aplicable en las relaciones entre las partes. 4. Se dará a un término un sentido especial si consta que tal fue la intención de las partes. 
En el mismo sentido, en la sentencia Penal Miguel Castro vs. Perú (2006), la Corte IDH analiza las violaciones a los derechos humanos originadas el 6 de mayo de 1992 dentro del Centro Penitenciario, consistentes en la muerte de 42 internos y el sometimiento a tratos crueles, inhumanos y degradantes de otros 322 internos. Como en el caso Almonacid, la Corte señaló que el Estado no debe dejar impunes estos delitos, debido a que esta obligación hace parte del derecho internacional imperativo. De igual forma, condenó la violencia sexual de acuerdo con la Convención Interamericana para Prevenir y Sancionar la Tortura.

La prohibición de la violencia de género como norma del ius cogens, así como el principio de igualdad, también son desarrollados en los casos Espinoza González vs. Perú y Veliz Franco vs. Guatemala. En el primero se analiza la violencia generada por agentes del Estado peruano entre los años 1980 y 2000, en particular, las prácticas generalizadas de violencia sexual que afectaron a las mujeres y que se enmarcaban en un contexto más amplio de discriminación, conductas en las que resultó afectada la señora Gladys Espinoza, quien fue privada de la libertad y sometida a abusos sexuales. En el segundo se estudió la falta de investigación del Estado de Guatemala, frente a la desaparición de una menor. En la sentencia Espinoza González la Corte reiteró que la prohibición de la tortura hace parte del dominio del ius cogens. De la misma forma, consideró que el principio de igualdad ante la ley y la no discriminación también deben entenderse en el contexto de obligaciones positivas en la salvaguardia de otros derechos (párr. 216).
2. Corte Constitucional

Igualmente, la Corte Constitucional ha utilizado el ius cogens en la solución de casos. En Sentencia C-251 de 2002 reiteró la línea jurisprudencial asumida en las Sentencias C-225/95, C-423/95, C-578/95, C-708/99, C-191/08 y C-191/08 respecto al carácter de ius cogens de las normas de derecho internacional humanitario. De otro lado, en la Sentencia C-620 de 2011, al analizar la Ley 1418 de 2010 que aprueba la "Convención Internacional para la protección de todas las personas contra las desapariciones forzadas", a pesar de reconocer la dificultad de determinar este tipo de normas señaló que las instancias judiciales internacionales deben ser las encargadas de calificar una norma internacional en términos de norma imperativa. También se rescata la Sentencia C-578 de 2002, que analizó la constitucionalidad del Estatuto de Roma y estableció que la mayoría de crímenes que contempla el Estatuto son normas de ius cogens, a pesar de que no evaluó estas normas en el contexto de concesión de amnistías.

También ha establecido algunos lineamientos respecto a las relaciones entre el derecho internacional y el derecho interno. Específicamente, en una de sus decisiones más controversiales, la relacionada con la declaración de exequibilidad del artículo XXI de la Ley 37 de 1961 "por el cual se aprueba el Tratado Americano de Soluciones Pacíficas (Pacto de Bogotá)", estableció que las decisiones de la Corte Internacional de Justicia (Nicaragua vs. Colombia, 2013) deben ser incorporadas mediante un tratado interna- 
cional. Decisión que responde a criterios más políticos que jurídicos, dado que desconoce por completo principios como la primacía del derecho internacional, pacta sunt servanda y buena fe, también reconocidos en el artículo 9 de la Constitución de Colombia (CConst., C-269/2014, M. González). No obstante lo anterior, señala que la Constitución se encuentra sometida al ius cogens.

Finalmente, en la Sentencia SU-195 de 1998, la Convención sobre los Derechos del Niño es elevada al rango de ius cogens, con base en la aceptación mayoritaria que de esta han hecho 155 países (Colombia no ha aceptado la posibilidad que el Comité de los Derechos del Niño pueda conocer quejas) y la Carta de las Naciones Unidas en los artículos 13 (recomendaciones de la Asamblea General de las Naciones Unidas), 55 literal C (promoción de los derechos humanos), 56 (compromiso de los Estados de realizar el propósito contemplado en el artículo 55) y el artículo 103 (obligación de cumplir con la Carta de las Naciones Unidas). En este sentido también resulta paradigmática la Sentencia T-302 de 2008, en donde se adopta la jurisprudencia de la Corte Europea de Derechos Humanos como criterio obligatorio al momento de dar una respuesta judicial que involucre los derechos del niño.

\section{B. Derecho blando}

Tan importante como lo mencionado ha sido el reconocimiento del derecho blando dentro de la jurisprudencia de la Corte Constitucional colombiana, pues la discusión en los últimos siete años ha pasado de su utilidad interpretativa a la necesidad que existe de acudir a este para la adopción de medidas razonables y adecuadas para la protección de los derechos, como puede ser la definición de políticas públicas. Igualmente, la Corte IDH ha empezado a incorporar el derecho blando, si bien no es clara la doctrina que justifique su utilización.

En primer lugar, es en la Sentencia T-235 de 2011 donde se reconoce el carácter imprescindible del derecho blando, al estudiar la tutela presentada por la gobernadora y representante legal de la Comunidad Indígena del Cañón del Río Pepitas (Dagua, Valle del Cauca), quien solicita la protección de distintos derechos por las omisiones de las autoridades públicas respecto a la prevención, ocurrencia y consecuencias de desastres naturales, como los que se vivieron en 2008 por la ola invernal. En esta decisión la Corte Constitucional señaló que instrumentos internacionales como la Estrategia y el Plan de Acción de Yokohama, y la Declaración de Hyogo de 2005 sobre reducción de desastres naturales, independientemente de su valor como fuentes del derecho, son:

Criterios y parámetros técnicos imprescindibles para la adopción de medidas razonables y adecuadas para la protección de los diversos intereses en juego, de manera que contribuyen al cumplimiento de la obligación central del juez en el estado de derecho, en el sentido de fallar con base en motivos razonables dentro del orden jurídico, y no me- 
diante su capricho o arbitrariedad. (CConst., T-235/2011, L. Vargas).

Adicionalmente, consideró tales instrumentos para formular una propuesta de política pública, logrando mostrar su importancia no solo en la argumentación y la resolución de un conflicto judicial, sino en el establecimiento de lineamientos que exijan al Estado modificar sus programas.

También son importantes los argumentos expuestos en la Sentencia T-371 de 2013 en relación con el respeto a los usos, costumbres, autonomía y territorio de las comunidades indígenas. En este caso la Comunidad Indígena Zenú, de Sincelejo, denunció que la alcaldía de dicho municipio realizó diferentes actividades en su territorio y el nombramiento de un dirigente sin su consentimiento. La Corte declaró que el marco de garantías constitucionales deber ser complementado con el bloque de constitucionalidad y el derecho blando, como la Declaración de las Naciones Unidas sobre los Derechos de los Pueblos Indígenas, de donde se derivan las pautas legales para la interpretación del juez constitucional.

Frente a la protección de los mismos derechos, en Sentencia T-384 A de 2014, respecto a la creación del Parque Nacional Natural Yaigojé Apaporis, acude al derecho blando para justificar el papel que han desempeñado las comunidades indígenas en el cuidado del medio ambiente, mencionando que el hecho que sea derecho blando no implica su desatención absoluta "cuando se trata de leer y comprender la preceptiva vinculante en el caso". Por ejemplo, aquí utilizó: 1) La Declaración autorizada, sin fuerza jurídica obligatoria, de principios para un consenso mundial respecto de la ordenación, la conservación y el desarrollo sostenible de los bosques de todo tipo, y 2) la Agenda 21, plan de acción exhaustivo del Sistema de Naciones Unidas, gobiernos y grupos principales respecto a la influencia del ser humano en el medio ambiente.

Ahora bien, como se mencionaba, la Corte IDH ha utilizado el derecho blando como criterio interpretativo sin determinar expresamente su importancia; no obstante, se observa que existe una clara influencia en la definición de los casos. En la sentencia Gonzáles Lluy vs. Ecuador (2015) debió analizar el contagio con el virus del VIH de una niña, luego de un procedimiento médico de transfusión de sangre, lo que le significó obvias y graves consecuencias en su salud y discriminación en el sistema educativo, razones por las cuales utilizó estas fuentes en la argumentación sobre el derecho a la salud, la educación y la discriminación en que viven las personas con VIH.

Respecto al derecho a la salud se basó en las Observaciones del Comité de Derechos Económicos, Sociales y Culturales, concretamente en la Observación General n. 3 relativa al VIH y los derechos del niño; en las Directrices internacionales sobre el VIH/SIDA de la Oficina del Alto Comisionado de las Naciones Unidas para los Derechos Humanos, específicamente en la sexta; y el Programa Conjunto de las Naciones Unidas sobre el VIH. En vir- 
tud de los anteriores instrumentos determinó: 1) los requisitos de disponibilidad, accesibilidad, aceptabilidad y calidad del derecho a la salud; 2) la implementación de una política, sobre una base sostenida e igualitaria, de un tratamiento adecuado, en donde se incluyen pruebas diagnósticas y tecnologías relacionadas seguras y eficaces para el VIH y fármacos antirretrovíricos del más alto nivel posible; y 3) acceso a información sobre escenarios que permitan sobrellevar en mejor forma la enfermedad.

Frente al derecho a la educación acudió a los criterios de disponibilidad, accesibilidad, aceptabilidad y adaptabilidad, establecidos por el Comité de Derechos Económicos, Sociales y Culturales. Igualmente, analizó el contexto de discriminación y estableció obligaciones precisas para el Estado de Ecuador, señalando el deber que tiene de promover la igualdad al acceso a la educación, la salud, entre otros derechos, con fundamento en la Recomendación General n. ${ }^{\circ} 28$ del Comité para la Eliminación de la Discriminación contra la Mujer.

Igualmente, en el caso Granier y otros (Radio Caracas Televisión) vs. Venezuela (2015), luego de analizar la negativa del gobierno venezolano a renovar la concesión al canal por su influencia en el golpe de Estado de abril de 2002, la Corte IDH utilizó el precedente del Tribunal Europeo de Derechos Humanos; la Declaración de Principios sobre la Libertad de Expresión, elaborada por la Relatoría sobre Libertad de Expresión de la Comisión Interameri- cana de Derechos Humanos; y la Observación General n. ${ }^{\circ} 34$ del Comité de Derechos Humanos de las Naciones Unidas.

Con base en lo mencionado concluyó: 1) la importancia de un periodismo ético y responsable, guiado por el principio de buena fe y la reflexión objetiva; 2 ) las restricciones del poder del Estado frente a la concesión de prebendas arancelarias, otorgamiento de frecuencias de radio y televisión y otros, con el objetivo de castigar medios de comunicación; 3) la prohibición de fijar regímenes onerosos para la apertura de medios de comunicación comunitarios y comerciales.

También incorporó argumentos del caso Defensor de Derechos Humanos y otros vs. Guatemala (2014), que determinó la responsabilidad del Estado por la violencia sistemática a los derechos de los defensores de derechos humanos luego de la firma de los acuerdos de paz. En esta sentencia se refirió a la Declaración sobre el derecho y deber de los individuos, los grupos y las instituciones de promover y proteger los derechos humanos y libertades fundamentales universalmente reconocidos.

Por último, se cita el caso Personas dominicanas y haitianas expulsadas contra República Dominicana (2014), relacionado con un patrón sistemático de expulsiones individuales y colectivas, sin que se garantizara el debido proceso. En esta oportunidad la Corte IDH se valió de las observaciones realizadas por el Comité de los Derechos del Niño, el Comité de 
Derechos Humanos, el Comité de las Naciones Unidas sobre la Eliminación de la Discriminación Racial (Observación n. ${ }^{\circ} 30$ ) y el proyecto de artículos sobre la protección de los derechos humanos de las personas expulsadas o en vía de expulsión de la Comisión de Derecho Internacional, y de su análisis surgen algunos lineamientos respecto al catálogo de derechos de personas en condiciones de migración: 1) el derecho a la nacionalidad de todos los niños en el momento de su nacimiento; 2) la garantía del debido proceso en el momento de determinar la licitud de la entrada; 3) condiciones dignas de detención; 4) asistencia consular; 4) contar con un intérprete; y 5) la prohibición de expulsiones colectivas.

El examen realizado a la jurisprudencia de la Corte IDH muestra la ampliación de los objetivos tradicionales del ius cogens, cambio que permite entender no solo el derecho internacional más allá del derecho de los tratados, sino también la fundamentación progresiva de los derechos humanos. Estos cambios también se visibilizan en normas que se entendían no eran vinculantes, pero la práctica judicial ha permitido caracterizarlas desde su importancia en la concreción de derechos y en la definición de políticas públicas.

\section{INFLUENCIA DEL DERECHO BLANDO EN LA JUSTICIA TRANSICIONAL}

Tanto los tribunales internacionales como los nacionales han sido relevantes en la creciente vinculatoriedad de las normas del derecho blando. Con base en esta perspectiva, se sostiene que la configuración de un campo normativo ${ }^{7}$ coherente de la justicia transicional, si bien pertenece al campo del derecho blando, permite establecer de forma clara los derechos de las víctimas desde distintos escenarios interpretativos, los cuales han cobrado vigencia como normas obligatorias (Sánchez, 2009, p. 27; Comisión Colombiana de Juristas, 2007).

El primer escenario tiene que ver con las tensiones entre la obligatoriedad de una respuesta penal a los delitos cometidos en el marco del conflicto armado y la necesidad de alcanzar la paz, así como con la indeterminación en el derecho internacional, particularmente en los Principios contra la Impunidad y los Principios para obtener Reparaciones. Prueba de lo mencionado es el cambio radical que se observa en el informe “Estudio sobre la legislación de amnistía y sobre su papel en la promoción de la protección de los derechos humanos",

7. Dicho campo normativo incluiría: el Conjunto de principios actualizado para la protección y la promoción de los derechos humanos mediante la lucha contra la impunidad (Principios contra la impunidad), los Principios y directrices básicos sobre el derecho de las víctimas de violaciones manifiestas de las normas internacionales de derechos humanos y de violaciones graves del derecho internacional humanitario a interponer recursos y reparaciones (Principios para obtener reparaciones), los Principios Rectores de los desplazamientos internos (Principios Deng), y los Principios sobre la Restitución de las Viviendas y el Patrimonio (Principios Pinheiro). (CConst., T- 821/2007, T-068/2010, C-810/ 2013, C-753/2013; Uprimny, Sánchez y Sánchez, 2014, p. 43; Dorado, 2013, p. 100) 
elaborado por Louis Joinet (1985), frente a los argumentos presentados en 1997, en donde se establece que las amnistías no contribuyen a la promoción de los derechos humanos, ya que se convierten en un obstáculo en la lucha contra la impunidad (Dorado, 2013, p. 82).

Otro referente de lo mencionado se encuentra en la actualización que realizó la experta independiente Diane Orentlicher, del "Conjunto de principios para la protección y la promoción de los derechos humanos mediante la lucha contra la impunidad", por mandato de la Comisión de Derechos Humanos, en el informe titulado "Estudio independiente, con inclusión de recomendaciones, sobre las mejores prácticas, para ayudar a los Estados a reforzar su capacidad nacional con miras a combatir todos los aspectos de la impunidad", donde si bien mantiene la apuesta por la prohibición total de amnistías, afirma que no existen respuestas únicas para atender las graves violaciones a los derechos humanos y propone como ejemplos a seguir la experiencia de Sudáfrica y Timor Oriental en lo que respecta a las amnistías condicionadas, a cambio de la revelación completa de la verdad y la realización de trabajos comunitarios, previo acuerdo con las víctimas, la aprobación de un tribunal y el cumplimiento de compromisos por parte de los autores (Orentlicher, 2004, párr. 5, 11, 12).

Estos principios han sido incorporados en el ordenamiento jurídico colombiano, y su violación constituye un incumplimiento de las normas obligatorias e inderogables (ius cogens), como por ejemplo, el deber de investigar, sancionar y reparar, máxime cuando los Principios contra la impunidad y los Principios para obtener reparaciones recogen las obligaciones suscritas por los Estados en otros tratados (CConst.: C-579/2013, J. Pretelt; C-370/2006, M. J. Cepeda et al.).

El segundo escenario está relacionado con la definición de una justicia transformadora, fundamentada en los derechos humanos, y con criterios claros frente a la responsabilidad corporativa. Para explicarlo se acude a los Principios Rectores de los Desplazamientos internos, elaborados por Francis Deng (Principios Deng) y los Principios sobre la Restitución de las Viviendas y el Patrimonio (Principios Pinheiro), con el propósito de aportar medidas más amplias que la reparación tradicional, como el derecho a la vivienda, la alimentación, etcétera, también sustentadas en los recientes informes del Relator sobre Justicia Transicional de la Organización de las Naciones Unidas. Del mismo modo, los principios, directrices y resoluciones sobre responsabilidad corporativa como el Pacto Global y los Principios Ruggie de responsabilidad corporativa, para tratar de contener los efectos del sistema económico neoliberal y su influencia en la producción de violencia.

En efecto, como se ha mencionado, estos principios se han visibilizado en la jurisprudencia constitucional e interamericana. Los Principios Deng fueron incorporados en el bloque de constitucionalidad en las Sentencias SU-1150 de 2000 y T-327 de 2001 (Sánchez, 2009, p. 27; Comisión Colombiana de Juristas, 2007, p. 
19), ampliando sus efectos no solo respecto a la búsqueda de una interpretación más favorable, sino también en la creación y aplicación de políticas públicas y la conducta de funcionarios públicos (CConst., T-327/2001).

Sin embargo, la aplicación más clara de los Principios Deng se dio en la Sentencia T-025 de 2004, en donde se determinó el alcance de los derechos de los desplazados, se definió de forma clara los deberes del Estado respecto a esta población, y se condenaron las omisiones de los servidores públicos frente al contexto generalizado de violación de derechos humanos, entre ellos el derecho a la paz, la salud, la educación, la vivienda y la existencia de medidas afirmativas, entre otros, plasmando también de forma clara el mandato de progresividad contenido en el Pacto Internacional de Derechos Económicos, Sociales y Culturales y en el Protocolo de San Salvador, respecto a la ampliación de la cobertura de los derechos sociales.

La Corte IDH ha utilizado los Principios Deng para la interpretación de los tratados internacionales que hacen parte del Sistema Interamericano de Derechos Humanos, específicamente del artículo 22 de la Convención Americana de Derechos Humanos, lo que le permitió fundamentar las condenas contra el Estado colombiano por la violación de múltiples derechos en las masacres de Ituango y Mapiripán, y en el desplazamiento de las comunidades del río Cacarica. Sin embargo, de acuerdo con Saffón y Uprimny (2007, pp. 4852), en las sentencias de Ituango y Mapiripán existen dos grandes deudas: la precariedad argumentativa para incorporar estas normas y la aplicación selectiva de algunos principios, lo que impidió extraer todas las consecuencias aplicables al caso, contrario a lo que se ordenó en la Sentencia T-025 de 2004 de la Corte Constitucional.

Así, la incorporación de los Principios Deng y su tránsito de derecho blando a norma de carácter vinculante es una realidad, que a pesar de su incipiente eficacia en los hacedores de política pública, son una importante herramienta para enfrentar las violaciones a los múltiples derechos y establecer garantías relacionadas no solo con la atención directa de las consecuencias específicas del desplazamiento, sino con la implementación de garantías en salud, educación, entre otros derechos, dadas las profundas raíces del conflicto armado en la desigualdad social y los obstáculos en la garantía de derechos.

Integrando los informes del Relator Especial sobre la verdad, la justicia, la reparación y las garantías de no repetición, Pablo de Greiff (2013, 2014), es necesario destacar la importancia de la vinculación de otros derechos violados a las víctimas, para de esta forma crear programas de mayor "complejidad" como las políticas de desarrollo y de seguridad.

Complementariamente, la Corte Constitucional ha entendido la transformación del componente responsabilidad social empresarial de norma del derecho blando a derecho vinculante, especialmente en la realidad del conflicto y los 
derechos de las víctimas. Esto lo ha señalado con claridad en la Sentencia T-781 de 2014, en donde conoce distintas tutelas presentadas por desplazados del conflicto armado, quienes aducen la violación de su derecho a la vivienda en la orden de desalojo por la invasión de predios de propiedad privada, ubicados en terrenos en donde tendría lugar un proyecto de hidrocarburos.

Teniendo en cuenta la jurisprudencia expedida sobre responsabilidad social corporativa (RSC) -C-608 de 2010; C-915 de 2010; T-247 de 2010 y T-129 de 2011- reconoce que las fuentes de la RSC se encuentran en su mayoría en las resoluciones y principios del derecho blando, y que revisten vital importancia en la medida que son coherentes con los objetivos económicos y sociales del artículo 333 de la Constitución de Colombia, al establecer parámetros claros respecto al cumplimiento de fines y valores constitucionales como la solidaridad, el trabajo y el respeto del medio ambiente, sobre todo cuando estas normas han sido consolidadas en tratados internacionales firmados por Colombia, por ejemplo en el Tratado de Libre Comercio con Canadá (CConst., C-608/2010, H. Sierra).

También señaló respecto al Pacto Global de las Naciones Unidas, de forma tímida pero precisa, que aun sin ser este un instrumento no vinculante resulta útil porque contiene elementos incluidos en la Constitución y por ende obligatorios para los sujetos que interactuán en el Estado social de derecho. Por tanto, aunque dicha Corporación inicialmente define la natu- raleza del Pacto Global como derecho blando, establece su obligatoriedad debido a su estrecha relación con la Constitución de Colombia. En consecuencia, determina los aspectos de la rsc teniendo en cuenta las normas del derecho blando, en particular la participación de otros actores (shakeholders): la sociedad, los sindicatos, organizaciones con interés social, entre otros.

Adicionalmente, "llama la atención" a las empresas de extracción respecto a sus obligaciones y la realización de los derechos humanos, a pesar de que lo mencionado no se visibiliza en la parte resolutiva de la Sentencia T-781 de 2014, por ejemplo, mediante una orden concreta o en la determinación de la influencia del desalojo en la implementación del proyecto por parte de Tecpetrol. En efecto, ordena la reubicación de la población desplazada, sin llegar a considerar los Principios Pinheiro y las Observaciones del Comité de Derechos Económicos, Sociales y Culturales, también relacionados en la sentencia, en el sentido de una restitución en condiciones de seguridad y dignidad, como la realización de consultas previas a la comunidad afectada.

Descrito el anterior contexto, es claro que las normas del derecho programático se han convertido en derecho vinculante, permitiendo comprender la justicia transicional desde aproximaciones que pueden ampliar la reparación clásica con la garantía integral de los derechos humanos, como es el caso de los Principios Deng. Del mismo modo, se observa cierta flexibilización respecto a la prohibición 
de amnistías. No obstante, persisten importantes retos, particularmente, frente al "miedo al rechazo estatal" y posiblemente "una retractación de las obligaciones" con base en el principio voluntarista del derecho internacional.

La mejor manera de superar el riesgo es transformando la visión tradicional del derecho internacional, que lo ubica en el derecho de los tratados, debido a la existencia de normas que escapan al consentimiento del Estado por su carácter esencial, tal y como lo establece la cV con la consagración del ius cogens, sobre todo cuando se impiden regresiones en la materia, categoría que como se mencionó es dinámica y está enriquecida por el derecho blando.

\section{CONCLUSIONES}

El examen realizado en este trabajo muestra que el ius cogens ha atravesado por distintas críticas y la fijación de ciertas restricciones. Los cuestionamientos se han basado en su presunta ambigüedad, así como en los riesgos de la ampliación de los principios y derechos que protege como "intereses esenciales de la comunidad internacional". Estas explicaciones han sido fundamentadas en el contexto del derecho internacional que está marcado por la voluntad y la manifestación expresa de consentimiento por parte de los Estados, de manera que su existencia y funcionamiento está por fuera del análisis del escenario real y actual del derecho internacional, ahora caracterizado por el surgimiento de nuevos actores y un papel creciente de las personas y los movimientos sociales.
El análisis detallado de las principales características del ius cogens respalda su vigencia y la transformación del derecho internacional, ya que la identificación de su contenido se condiciona a las necesidades que en cada momento histórico define la comunidad internacional y no en la existencia de una norma en sentido formal "escrita", definición que a pesar de su amplitud conceptual no es ambigua, puesto que existen criterios para su determinación, como pueden ser el bien común, la realización de la justicia y la preservación de la paz. Igualmente, se aminoran los riesgos de una posible retractación del Estado en sus obligaciones, sobre todo cuando no es posible debido a la inderogabilidad de estas normas. Evidencia empírica de lo mencionado se encuentra en la jurisprudencia internacional y nacional, en materia de ampliación de los derechos que hacen parte de aquellos "intereses esenciales de la comunidad internacional”, como puede ser la prohibición de la violación del derecho a la vida, no solo limitada al homicidio, la tortura, entre otros, sino extendida a la privación del derecho de vivir dignamente.

De otro lado, es evidente la progresiva utilización del derecho blando como norma vinculante, con múltiples efectos en la interpretación y la determinación de contenidos de los derechos humanos y en la estructuración de políticas públicas, campos donde tiene un papel protagónico el activismo judicial. Debido a estas funciones que ha cumplido el derecho blando es de esperar su influencia en la evolución y la permanente actualización de los contenidos del ius cogens, así como en la misma Constitución. 
En este contexto, la justicia transicional coexiste en un campo normativo de continuas relaciones entre el ius cogens y el derecho blando, en donde es evidente que este último ha orientado las directrices tradicionales que deben seguirse en la implementación de la justicia transicional, a pesar del cierto margen de discrecionalidad de los Estados, ya que también se ha diversificado hacia la garantía de los derechos económicos, sociales y culturales, específicamente con los Principios Deng y la definición de responsabilidades corporativas, como es el caso del Pacto Global de las Naciones Unidas.

\section{Referencias}

1. Abello-Galvis, R. (2011). Introducción al estudio de las normas de ius cogens en el seno de la Comisión de Derecho Internacional, CDI. Vniversitas, (123), 75-104. Obtenido de scielo: http://www.scielo.org.co/ scielo.php?script=sci_arttext\&pid=S004190602011000200004\&lng=en\&tlng=es

2. Acosta, J. y Duque, A. (2008). Declaración Universal de los Derechos Humanos ¿Normas del lus Cogens? International Law, (12), 13-34. Obtenido de scielo: http:// www.scielo.org.co/pdf/ilrdi/n12/n12a02. pdf

3. Cançado Trindade, A. A. (1999). Voto razonado caso de los Niños de la Calle vs. Guatemala. Corte Interamericana de Derechos Humanos.
4. Cançado Trindade, A. A. (2007). La ampliación del contenido material del ius cogens. Obtenido de oas: http://www.oas.org/dil/ esp/3\%20-\%20cancado.DM.MR.1-16.pdf

5. Cançado Trindade, A. A. (2004). Voto razonado caso Tibi vs. Ecuador. Corte Interamericana de Derechos Humanos.

6. Cebada, A. (2002). Los conceptos de obligación erga omnes, ius cogens y violación grave a la luz del nuevo proyecto de la cdi sobre responsabilidad de los Estados por hechos ilícitos. Revista Electrónica de Estudios Internacionales. Obtenido de reei: http://www.reei.org/index.php/revista/ num4/archivos/Cebada.PDF

7. Cepeda, E. (2013). Impunidad y paz ¿Es posible una solución al conflicto en Colombia? Cultura Científica, (11). Obtenido de revistasjdc: http://www.revistasjdc.com/main/ index.php/ccient/article/view/218/210

8. Comisión Colombiana de Juristas. (2015a). II Informe de seguimiento a la aplicación en Colombia de las recomendaciones del Relator Especial sobre la situación de los derechos humanos y libertades fundamentales de los pueblos indígenas. Obtenido de coljuristas: http://www.coljuristas.org/ documentos/libros_e_informes/informe_ derechos_pueblos_indigenas_2010-2013. pdf

9. Comisión Colombiana de Juristas. (2015b). Comité contra la Tortura de la ONU reitera 
su preocupación por la tortura en Colombia. Obtenido de coljuristas: http://www. coljuristas.org/documentos/documento. php?id_doc $=479 \&$ idioma $=$ es $\&$ grupo $=4$

10. Comisión Colombiana de Juristas. (2007). Principios internacionales sobre impunidad y reparaciones. Bogotá: Opciones Gráficas Editores Ltda. Obtenido de coljuristas: http://www.coljuristas.org/documentos/libros_e_informes/principios_sobre_impunidad_y_reparaciones.pdf

11. Corte Constitucional de Colombia. Sentencia SU-195 de 1998 (M. P.: Vladimiro Naranjo Mesa; mayo 7 de 1998).

12. Corte Constitucional de Colombia. Sentencia SU-1150 de 2001 (M. P.: Eduardo Cifuentes Muñoz; agosto 30 de 2000).

13. Corte Constitucional de Colombia. Sentencia T-327 de 2001 (M. P.: Marco Gerardo Monroy; marzo 1 de 2001).

14. Corte Constitucional de Colombia. Sentencia C-251 de 2002 (M. P.: Eduardo Montealegre Lynett y Clara Inés Vargas Hernández; abril 11 de 2002).

15. Corte Constitucional de Colombia. Sentencia C-578 de 2002 (M. P.: Manuel José Cepeda Espinoza; julio 30 de 2002).

16. Corte Constitucional de Colombia. Sentencia T-025 de 2004 (M. P.: Manuel José Cepeda Espinoza; enero 22 de 2004).
17. Corte Constitucional de Colombia. Sentencia C-370 de 2006 (M. P.: Cepeda y otros; mayo 18 de 2006).

18. Corte Constitucional de Colombia. Sentencia T-821 de 2007 (M. P.: Catalina Botero Marino; octubre 5 de 2007).

19. Corte Constitucional de Colombia. Sentencia T-302 de 2008 (M. P.: Jaime Córdoba Triviño; abril 3 de 2008).

20. Corte Constitucional de Colombia. Sentencia C-608 de 2010 (M. P.: Humberto Antonio Sierra Porto; agosto 3 de 2010).

21. Corte Constitucional de Colombia. Sentencia T-068 de 2010 (M. P.: Jorge Ignacio Pretelt; 4 de febrero de 2010).

22. Corte Constitucional de Colombia. Sentencia T-235 de 2011 (M. P.: Luis Ernesto Vargas Silva; marzo 31 de 2011).

23. Corte Constitucional de Colombia. Sentencia C-620 de 2011 (M. P.: Juan Carlos Henao; agosto 18 de 2011).

24. Corte Constitucional de Colombia. Sentencia T-371 de 2013 (M. P.: Jorge Iván Palacio Palacio; junio 27 de 2013).

25. Corte Constitucional de Colombia. Sentencia C-579 de 2013 (M. P.: Jorge Ignacio Pretelt Chaljub; agosto 28 de 2013).

26. Corte Constitucional de Colombia. Sentencia C- 753 de 2013 (M. P.: Nilson Pinilla Pinilla; mayo 15 de 2013). 
27. Corte Constitucional de Colombia. Sentencia C-810 de 2013 (M. P.: Mauricio González Cuervo; octubre 30 de 2013).

28. Corte Constitucional de Colombia. Sentencia T-781 de 2014 (M. P.: Jorge Ignacio Pretelt Chaljub; octubre 20 de 2014).

29. Corte Constitucional de Colombia. Sentencia T-384 A de 2014 (M.P. Gabriel Eduardo Mendoza Martelo; Junio 17 de 2014).

30. Corte Constitucional de Colombia. Sentencia C-269 de 2014 (M. P.: Mauricio González Cuervo; mayo 2 de 2014).

31. Corte Interamericana de Derechos Humanos. (1999). Caso de los Niños de la Calle (Villagrán Morales y otros) vs. Guatemala. Excepciones Preliminares, Fondo, Reparaciones y Costas (noviembre 19, 1999).

32. Corte Interamericana de Derechos Humanos. (2004). Caso Tibi vs. Ecuador. Excepciones Preliminares, Fondo, Reparaciones y Costas (septiembre 7, 2004).

33. Corte Interamericana de Derechos Humanos. (2006). Caso Almonacid Arellano y otros vs. Chile. Excepciones Preliminares, Fondo, Reparaciones y Costas (septiembre 26, 2006).

34. Corte Interamericana de Derechos Humanos. (2006). Caso Penal Miguel Castro vs. Perú. Excepciones Preliminares, Fondo, Reparaciones y Costas (noviembre 25, 2006).
35. Corte Interamericana de Derechos Humanos. Caso Veliz Franco y otros vs. Guatemala. Excepciones Preliminares, Fondo, Reparaciones y Costas (mayo 19, 2014).

36. Corte Interamericana de Derechos Humanos. (2014). Caso Espinosa González vs. Perú. Excepciones Preliminares, Fondo, Reparaciones y Costas (noviembre 20, 2014).

37. Corte Interamericana de Derechos Humanos. (2014). Caso Defensor de Derechos Humanos y otros vs. Guatemala. Excepciones Preliminares, Fondo, Reparaciones y Costas (julio 23, 2015).

38. Corte Interamericana de Derechos Humanos. (2014). Caso Personas dominicanas y haitianas expulsadas vs. República Dominicana. Excepciones Preliminares, Fondo, Reparaciones y Costas (agosto 28, 2014).

39. Corte Interamericana de Derechos Humanos. (2015). Caso Gonzáles Lluy vs. Ecuador. Excepciones Preliminares, Fondo, Reparaciones y Costas (septiembre 2, 2015).

40. Corte Interamericana de Derechos Humanos. (2015). Caso Granier y otros (Radio Caracas Televisión) vs. Venezuela. Excepciones Preliminares, Fondo, Reparaciones y Costas (junio 22, 2015).

41. Chicharro, A. (2012). El carácter de soft law de los instrumentos internacionales sobre desarrollo sostenible. En Congreso 
Internacional de Estudios del Desarrollo. Obtenido de: http://congresoreedes.unican.es/actas/PDFs/69.pdf

42. Damián, P. (2012). Impacto de las Normas del Soft Law en el desarrollo internacional de los derechos humanos. Revista Electrónica del Instituto de Investigaciones "Ambrosio L. Gioja", (8). Obtenido de derecho: http://www.derecho.uba.ar/revistagioja/ articulos/R0008A006_0004_investigacion.pdf

43. De Greiff, P. (Agosto 23 de 2013). Report to the General Assembly on the relevance of justice and rights consideration to sustainable development. General Assembly, United Nations A/68/345. Obtenido de: https://documents-dds-ny.un.org/doc/UNDOC/GEN/N13/438/64/PDF/N1343864. pdf?OpenElement

44. De Greiff, P. (Octubre 14 de 2014). Report of the Special Rapporteur on the promotion of truth, justice, reparation and guarantees of non-recurrence. General Assembly, United Nations A/69/158. Obtenido de: https://documents-dds-ny.un.org/doc/UNDOC/GEN/N14/564/67/PDF/N1456467. pdf?OpenElement

45. Díez de Velasco, M. (2009). Instituciones de Derecho Internacional Público. Madrid: Tecnos.

46. Domínguez Cebrián, B. (Noviembre de 2014). Casi 36 millones de personas viven aún en condiciones de esclavitud. Recuperado de El País: http://internacional.elpais. com/internacional/2014/11/17/actualidad/1416244426_315264.html

47. Dorado, J. (2013). Justicia Transicional, Persecución Penal y Amnistías. Derechos y Libertades, (28), 81-113.

48. Gamboa, C. (2007). El caso colombiano: la transición fallida. En G. Hoyos (Ed.), Las víctimas frente a la búsqueda de la verdad y la reparación en Colombia. Bogotá: Pontificia Universidad Javeriana/ Goethe Institut/Pensar.

49. Giraldo, J. (2009). Conflicto y derecho internacional humanitario en Colombia. En Seminario Internacional sobre Colombia, Conflicto y Derecho Internacional Humanitario. España: Universidad Carlos III de Madrid. Obtenido de javiergiraldo: http:// www.javiergiraldo.org/IMG/pdf/conflictoyDIH.pdf

50. Harvey, D. (2000). Espacios de Esperanza. Madrid: Akal.

51. López, M. y Sánchez, A. (2008). La armonización del derecho internacional de los derechos humanos con el derecho penal coIombiano. International Law, (12), 318-351.

52. Marín López, D. (2012a). Los Principios Ruggie y los Informes del Pacto Global dentro de la figura Instrumentos de "Soft Law" que vinculan a Empresas dentro del mar- 
co de la onU. En D. Marín López, Relatoría "Poder, globalización y derecho". Obtenido de relatorestematicos: https://relatorestematicos.uniandes.edu.co/images/stories/ relatorias/pdfs/GPD/Art2Daniel.pdf

53. Marín López, D. (2012b). Consideraciones acerca de los instrumentos "sof law" internacionales dentro de un posible Marco de Aplicación de los Principios Ruggie. En D. Marín López, Relatoría "Poder, globalización y derecho". Recuperado de relatorestematicos: https://relatorestematicos. uniandes.edu.co/images/stories/relatorias/pdfs/GPD/Art3Daniel.pdf

54. Orentlicher, D. (2004). Estudio independiente, con inclusión de recomendaciones, sobre las mejores prácticas, para ayudar a los estados a reforzar su capacidad nacional con miras a combatir todos los aspectos de la impunidad. Comisión de Derechos Humanos, Organización de las Naciones E/CN.4/2004/88. Obtenido de: https://documents-dds-ny.un.org/doc/UNDOC/GEN/G04/113/58/PDF/G0411358. pdf?OpenElement

55. Pérez Luño, A. E. (1995). Derechos Humanos, Estado de Derecho y Constitución. Madrid: Tecnos.

56. Rajagopal, B. (2010). El derecho internacional desde abajo: el desarrollo, los movimientos sociales y la resistencia del Tercer Mundo. Bogotá: Instituto Latinoamericano de Servicios Legales Alternativos.
57. Saffón, M. y Uprimny, R. (2007). Las masacres de Ituango Colombia: una sentencia de desarrollo incremental. Cejil, (3), 46-57.

58. Sánchez, B. (2009). Cuando los Derechos son la Jaula. Trasplante Rígido del Soft Law para la Gestión del Desplazamiento Forzado. Estudios Políticos, (35), 11-32.

59. Sévane, G. y Puppo, A. (2012). Acerca de la Existencia del lus Cogens Internacional: Una Perspectiva Analítica y Positivista. Isonomía, (36), 7-47. Obtenido de scielo: http://www.scielo.org.mx/ scielo.php?script=sci_arttext\&pid=S140502182012000100001\&lng=es\&tlng=es

60. Toro, M. (2006). El fenómeno del Soft Law y las Nuevas Perspectivas del Derecho Internacional. Anuario Mexicano de Derecho Internacional, VI, 513-549. Obtenido de biblio.juridicas: http://biblio.juridicas.unam. $\mathrm{mx} /$ revista/pdf/Derecholnternacional/6/ art/art12.pdf

61. Uprimny, R. (2013). Intervención en la Corte Constitucional con ocasión de la demanda de constitucionalidad contra el Acto Legislativo No. 01 de 2012. Obtenido de dejusticia: http://www.dejusticia.org/files/ r2_actividades_recursos/fi_name_recurso.556.pdf

62. Uprimny, R. y Botero Marino, C. (2006). ¿Justicia Transicional sin Transición? Verdad, Justicia y Reparación para Colombia. Bogotá: Centro de Estudios de Derecho, Justicia y Sociedad. 
63. Uprimny, R., Sánchez, L. y Sánchez, N. cholnternacional/numero/10/art/art1. (2014). Justicia para la paz. Crímenes atrohtm ces, derecho a la justicia y paz negociada. Bogotá: Dejusticia.

65. Zelada, C. (2002). Ius Cogens y Derechos Humanos: luces y sombras para una ade-

64. Vallarta, J. (2010). La argumentación jurícuada limitación de conceptos. Agenda Indica en torno al lus Cogens internacional. ternacional, (17), 129-156. Obtenido de reAnuario Mexicano de Derecho Internacional, x. Obtenido de biblio.juridicas: http:// vistas.pucp: http://revistas.pucp.edu.pe/ biblio.juridicas.unam. $\mathrm{mx} /$ revista/Dereindex.php/agendainternacional/article/ viewFile/8239/8545 